\title{
BEYOND THE LADDER OF PARTICIPATION: AN ANALYTICAL TOOLKIT FOR THE CRITICAL ANALYSIS OF PARTICIPATORY MEDIA PROCESSES ${ }^{1}$
}

\author{
Nico CARPENTIER ${ }^{2}$
}

\section{Tradução Simone do Vale - PPGMC/UFF}

Resumo: A pesquisa participativa enfrenta hoje três desafios: como abordar a teorização e a conceituação da participação; como fundamentar a pesquisa com modelos analíticos; e como avaliar os resultados de pesquisa. Este artigo visa discutir esses três problemas por meio da distinção entre as duas abordagens fundamentais (uma sociológica e uma política) da teoria participativa e desenvolver um modelo analítico de quatro níveis e doze etapas, cujo funcionamento está vinculado à abordagem política. Neste modelo analítico, emprega-se uma série de conceitos-chave: processo, campo, ator, momento de tomada de decisão e poder. O problema normativo-avaliativo é abordado por meio do recurso à perspectiva crítica para a avaliar o anseio societal por determinadas intensidades participativas. Esta perspectiva crítica - potencialmente - acrescenta um derradeiro $13^{\circ}$ nível normativo ao modelo analítico.

Palavras-chave: participação; teoria participativa; modelo analítico; o crítico; poder; processo; campo; ator; momento de tomada de decisão.

Abstract: Participatory research is facing three challenges-how to deal with the theoretisation and conceptualisation of participation; how to support the research with analytical models; and how the evaluate the research outcomes. This article aims to address these three problems by distinguishing two main approaches (a sociological and a political) in participatory theory and developing a four-level and 12-step analytical

1 Originalmente publicado em: CARPENTIER, Nico. Beyond the Ladder of Participation: An Analytical Toolkit for the Critical Analysis of Participatory Media Processes, Javnost - The Public, 23:1, 70-88, 2016. DOI: 10.1080/13183222.2016.1149760.

2 Professor do Departamento de Informática e Mídia na Uppsala University, Suécia. Também é Professor Associado do Departamento de Estudos de Comunicação na Vrije Universiteit Brussel, Bélgica, e da Charles University, República Tcheca. Pesquisador Associado na Loughborough University, Inglaterra, e na Cyprus University of Technology, Chipre. 
model that functions within the political approach. In this analytical model, a series of key concepts are used: process, field, actor, decision-making moment and power. The normative-evaluative problem is addressed by reverting to the critical perspective to evaluate the societal desirability of particular participatory intensities. This critical perspective - potentially — adds a 13th and final normative layer to the analytical model.

Keywords: participation; participatory theory; analytical model; the critical; power; process; field; actor; decision-making moment 


\section{míDiA

Introdução

Motivados pelo interesse nas mídias online e na promessa de emancipação inerente à sua natureza decentralizada, os Estudos de Mídia sobre as práticas participativas se tornaram populares novamente. Esse aumento do interesse nas práticas participativas também provocou o ressurgimento de uma série de problemas, os quais se situam em três níveis distintos, embora interligados.

Em primeiro lugar, quase não existe consenso quanto às maneiras como a participação deve ser teorizada, ou mesmo definida. Pode-se apenas comemorar e abraçar a pluralidade resultante das abordagens da participação, mas, ao mesmo tempo, é necessário clareza para garantir que os diálogos acadêmicos possam ser organizados e que os pesquisadores possam aproveitar mais o trabalho uns dos outros para melhor compreender o papel da participação nas sociedades contemporâneas. Em segundo lugar, também há uma considerável indefinição quanto aos modos como se deveria pesquisar a participação. Todas as práticas sociais são caracterizadas pela complexidade, porém, no caso do processo participativo, essa complexidade é ainda mais acentuada pelas disputas discursivas e materiais intimamente ligadas aos processos participativos. Mal se debate (ou desenvolve) modelos analíticos, que poderiam fundamentar melhor os pesquisadores na abordagem dessa complexidade. Em terceiro lugar, não há debate suficiente sobre como a participação deveria ser avaliada. Em algumas ocasiões, tem-se a impressão de que qualquer tipo de ação social pode ser classificada como participativa e, então, celebrada como parte de uma trajetória rumo ao nirvana democrático. É necessário reconhecer a natureza ideológica da participação, o que suscita discussões normativas quanto ao interesse por determinadas intensidades participativas. Nesse nível, a perspectiva crítica proporciona um ponto de ancoragem normativa que facilitará o processo de posicionamento do viés da análise.

Este artigo pretende contribuir para essas três áreas problemáticas da pesquisa participativa, primeiro por oferecer uma reflexão sobre a teoria (da mídia) participativa, argumentando que as duas principais abordagens (uma sociológica e uma política) podem ser distinguidas para, assim, conceder um simples ponto de partida rumo ao labirinto da teoria participativa. Esta segunda abordagem, a política, será usada para desenvolver um modelo analítico, que consiste de quatro níveis e doze etapas para orientar os 
pesquisadores que preferem a abordagem política para tratar as complexidades das análises de poder inerentes à abordagem política. Sobretudo, este artigo retornará à discussão normativa, recorrendo à perspectiva crítica, que pode ser usada para avaliar a conveniência societal de intensidades participativas específicas. Esta perspectiva crítica está intimamente associada à abordagem política, uma vez que ambas partilham um enfoque no poder, embora, ao mesmo tempo, a perspectiva crítica seja diferente por levantar a questão da mudança social e, em particular, da "democratização da democracia" (GIDDENS, 2002, p. 93).

Ao mesmo tempo, considerando o escopo um tanto ambicioso deste artigo, tornase necessária uma série de esclarecimentos. O modelo analítico desenvolvido neste artigo não discute métodos de pesquisa em detalhe, mas oferece um enquadramento analítico no qual uma variedade de métodos pode ser empregada, dependendo do nível do modelo analítico pesquisado e da natureza exata do processo participativo que se busca pesquisar. Ao contrário, este artigo se refere a pesquisas prévias, usando estes estudos de caso como exemplos mas, principalmente, para estruturar, aprimorar e explicitar os enquadramentos analíticos usados anteriormente (ver CARPENTIER, 2011). Obviamente, o artigo também não tem a ambição de apresentar o modelo analítico perfeito para o estudo da participação midiática (ou da participação em outros domínios sociais), mas, apesar disso, ele visa oferecer uma contribuição para a pesquisa participativa, além de um diálogo muito necessário sobre como lidar com as complexidades da pesquisa de participação.

\section{Abordagens da Participação}

A literatura sobre participação, incluindo mídia e participação, produziu muitos posicionamentos diferentes (para dois debates recentes relativos à mídia, ver, por exemplo, JENKINS \& CARPENTIER [2013] e ALLEN et al. [2014]). Possivelmente, as duas abordagens da participação podem ser distinguidas nesses debates: uma abordagem sociológica e uma abordagem (de ciência) política ${ }^{3}$ (ver, também, LEPIK, 2013). A abordagem sociológica define participação como tomar parte em determinados processos

\footnotetext{
3 Estas duas abordagens se referem ao uso dominante do conceito de participação nesses campos acadêmicos. Isto não implica que este uso dominante é o único, nem que esses campos são homogêneos. A abordagem dos estudos políticos, no que se refere à participação, será doravante denominada abordagem política, para fins de simplificação.
} 
sociais, uma definição que abrange um campo demasiado amplo. Nessa abordagem, participação inclui muitos (senão todos) os tipos de interação humana, combinados às interações com textos e tecnologias. O poder não está excluído dessa abordagem, mas permanece como um dos muitos conceitos secundários que a sustentam. Um exemplo de como a participação é definida nessa abordagem é a definição de MELUCCI (1989, p. 174), na qual ele afirma que a participação tem um duplo sentido: "Ela significa tanto tomar parte, isto é, agir de maneira a promover os interesses e necessidades de um ator, quanto pertencer a um sistema, identificando-se com os 'interesses gerais' de uma comunidade". Nos debates mencionados anteriormente, também podemos encontrar um exemplo dessa abordagem formulado por um dos autores:

\begin{abstract}
A crítica da participação soa um pouco frustrante quanto às suas promessas irrealizadas, mas que sempre foram ilusórias. Tentei desenvolver uma noção pragmática de participação. As expectativas pessoais do pesquisador quanto ao progresso ou equilíbrio do poder não deveriam fazer parte dela. Eu abordo a participação mais como um termo técnico, um modus operandi, livre de conotação política. A participação simplesmente descreve como os usuários, de um jeito ou de outro, contribuem ou participam ao utilizar um serviço ou uma plataforma (SCHÄFER, IN: ALLEN et al. 2014, p. 1142).
\end{abstract}

A abordagem sociológica, por exemplo, acaba por classificar o consumo como participativo porque os consumidores fazem parte de uma cultura do consumo e exercem escolhas de consumo (LURY 2011, p. 12). O rótulo da participação também se aplica à prática esportiva, como exemplificado pelo uso frequente do conceito de participação por Delaney \& Madigan (2009) na sua introdução à sociologia dos esportes. Podemos encontrar uma abordagem semelhante naquilo que se classificou como participação cultural, pelo qual a participação é definida como exposição, fruição e acesso individual (ou cultural) à arte, complementados em certos casos pela criação artística individual (ou cultural). Como descrevem Vander Stichle \& Laermans (2006, p. 48): “A princípio, o comportamento da participação cultural abrange tanto as práticas de recepção públicas quanto privadas, assim como as formas ativas e interativas de participação cultural." Na prática, isso implica que o conceito de participação se aplica a práticas como assistir um concerto ou visitar um museu.

Nos Estudos de Mídia, a abordagem sociológica pode ser encontrada, por exemplo, na maneira como Carey (2009, p. 15) define o modelo ritual da comunicação em Communication as Culture, como a "representação de crenças comuns", por meio das 
quais a união é criada e mantida, sem menosprezar as inúmeras forças conflitantes que caracterizam o social. Para Carey, o modelo ritual da comunicação está explicitamente ligado às noções de “'partilha', 'participação', 'associação', 'companheirismo' e a 'propriedade de uma fé comum'” (2009, p. 15), segundo as quais as pessoas são (fazem) parte de uma cultura por meio da participação ritualística nessa mesma cultura. Os meios de comunicação (de massa), como os jornais (usados por Carey como exemplo), desempenham um papel crucial ao convidar os leitores a participarem de uma configuração cultural, interpelando-os - para usar um conceito althusseriano - a fazer parte da sociedade ao oferecer-lhes posições de sujeito ou, de acordo com Carey, papéis sociais, com os quais eles precisam se identificar (ou não se identificar):

\begin{abstract}
Sob uma perspectiva ritualística, então, a notícia não é informação, mas drama. Ela não descreve o mundo, mas retrata uma arena de forças e ações dramáticas; ela existe somente no tempo histórico; e ela estimula a participação desde que se assuma papéis sociais, em geral, indiretamente, em relação à própria notícia (CAREY, 2009, p. 21).
\end{abstract}

Mais uma vez, esse tipo de participação ritual ${ }^{4}$ define a participação como tomar (e fazer) parte de textos midiáticos - no caso de Carey - por meio de uma série de interações. Outros também têm usado o conceito de participação ritual (e a abordagem sociológica da participação que lhe é correlata) em relação à mídia (REAL, 1996; DAYAN \& KATZ, 2009, p. 120), festividades (ROEMER, 2007) e às artes (BRADDOCK, 2009).

Em contraste, a abordagem política produz uma definição muito mais restritiva de participação, referindo-se à equalização das desigualdades de poder em determinados processos de tomada de decisão (ver CARPENTIER, 2011; CARPENTIER, DAHLGREN \& PASQUALI, 2014). Consequentemente, a participação passou a ser definida como a equalização das relações de poder entre atores privilegiados e nãoprivilegiados em processos formais ou informais de tomada de decisão.

\footnotetext{
4 Curiosamente, Carey (2009) não usa o conceito de participação ritual em Communication as Culture. Ele usa "ritual de participação" (2009, p. 177), que se refere a um processo muito diferente; a saber, o esvaziamento do significante participação como uma estratégia elitista. Esse uso do conceito de participação pode ser encontrado, principalmente, no sétimo capítulo de Communication as Culture ('The History of the Future', co-escrito com John J. Quirk), está muito mais alinhado com a abordagem política da participação.
} 
No campo da teoria democrática, por exemplo, o livro Participation and Democratic Theory ${ }^{5}(1970)$ de Pateman é altamente instrumental por demonstrar a importância do poder na definição de participação, podendo ser considerado um exemplo chave da abordagem política da participação. As duas definições de participação introduzidas pela autora são aquelas da participação parcial e total. Pateman define a participação parcial como "um processo no qual duas partes ou mais influenciam a tomada de decisões umas das outras, mas apenas uma parte detém o poder sobre a decisão final" (1970, p. 70), enquanto a participação total é vista como "um processo onde cada membro individual de um corpo de tomada de decisão tem poder igual para determinar o resultado das decisões" (1970, p. 71). Também no campo do planejamento urbano, em seu seminal artigo A Ladder of Citizen Participation ${ }^{6}$ (ver mais adiante), Arnstein (1969, p. 216) associa explicitamente a participação ao poder, afirmando que "a participação cidadã é um termo categórico para poder cidadão".

A abordagem política também permite enfatizar que a participação é um objeto de disputa, e que os diferentes projetos ideológicos (e seus proponentes) defendem diferentes intensidades participativas ${ }^{7}$. Versões mais minimalistas da participação tendem a proteger as posições de poder dos atores privilegiados (elite) em detrimento dos atores nãoprivilegiados (não-elite), sem excluir esses últimos totalmente. Em contrapartida, versões mais maximalistas da participação defendem um equilíbrio completo entre todos os atores (que protege os atores não-privilegiados).

$\mathrm{Na}$ abordagem política, o uso mais restritivo da noção de participação carece de uma demarcação mais clara quanto à série de conceitos relacionados que, na abordagem sociológica, são usados alternadamente em geral. Um conceito chave é engajamento ${ }^{8}$, que

5 PATEMAN, Carole. Participação e Teoria Democrática. Rio de Janeiro: Paz e Terra, 1992 (N. da T.).

6 ARnSteIN, Sherry R. Uma Escada da Participação Cidadã. PARTICIPE: Revista da Associação Brasileira para o Fortalecimento da Participação, Porto Alegre/Santa Cruz do Sul, v. 2, n. 2, p. 4-13, jan. 2002 (N. da T.).

7 Uma complicação é que o próprio conceito de participação em si é parte dessas disputas de poder, o que o torna altamente contingente. O significado de participação é parte de uma "política da definição" (FIERLBECK, 1998, p. 177), já que a sua articulação se transforma dependendo do enquadramento ideológico que dele se utiliza.

8 Apesar da sua importância, isso não será usado neste artigo para não complicar demais as coisas. 
Dahlgren (2013, p. 25) define como "disposição subjetiva que provoca [a] percepção [da participação]", para distingui-la da participação em si. Em trabalho anterior, Dahlgren (2009) argumenta que a sensação de ser convidado, comprometido e/ou emancipado, mas, também, a inclinação positiva em relação à política (e ao social) são componentes cruciais do engajamento. No seu circuito das culturas cidadãs, Dahlgren ainda enfatiza a importância de conhecimento, confiança, identidades e valores para (aumentar) o engajamento (além de elementos mais materialistas como práticas e espaços). Engajamento, portanto, é diferente de participação (na abordagem política) porque engajamento se refere à criação, ou existência, de um vínculo social entre indivíduos ou grupos com uma comunidade política mais ampla, cuja finalidade é proteger ou estreitálo.

Outros conceitos relacionados, embora ainda distintos, são acesso e interação. Em um trabalho anterior, argumentei que acesso se refere à instituição da presença, enquanto interação se refere à criação de relações sociocomunicativas (CARPENTIER, 2011, pp. 130-131). Como conceito, acesso faz parte da linguagem cotidiana, o que torna as definições claras bastante incomuns. Ao mesmo tempo, acesso - como conceito - é usado em uma imensa variedade de campos (acadêmicos), o que pode ser útil para aprofundar a compreensão desse conceito. A geografia é uma área em que acesso é usado com frequência, sempre que o acesso a espaços e lugares específicos é tematizado. Análises mais históricas (espaciais) tratam do acesso à terra e da demarcação de campos comuns (NEESON, 1996), enquanto análises mais contemporâneas enfocam o acesso a outros recursos como alimentação (MORTON et al., 2008) e água (WEGERICH \& WARNER, 2004). A importância da presença para a definição de acesso também pode ser ilustrada por uma série de exemplos dos Estudos de Mídia: no caso do discurso sobre a inclusão digital, por exemplo, o foco se concentra no acesso às tecnologias de comunicação (online), as quais, por sua vez, permitem que as pessoas acessem conteúdo midiático. Em ambos os casos, acesso implica adquirir presença (para tecnologia ou conteúdo midiático). $\mathrm{O}$ acesso também figura nas discussões de fundo mais tradicionais sobre as mídias, nas quais ele ganha ainda outro sentido. Aqui, acesso significa ganhar uma presença nas organizações midiáticas, que geram as oportunidades para que as pessoas possam se fazer ouvir (por meio de comentários). 


\section{míDiA

\section{Análise crítica dos processos midiáticos participativos}

Interação é um segundo conceito que precisa ser distinguido da participação. Se olharmos para o trabalho do filósofo argentino Bunge (1977, p. 259), podemos encontrar a traiçoeiramente simples e genérica definição de interação - "duas coisas diferentes, $\mathrm{x}$ e $\mathrm{y}$, interagem quando cada uma afeta a outra" - combinada com o seguinte postulado: “Todas as coisas afetam e são afetadas por outras coisas". A interação também possui uma longa história na teoria sociológica, onde ela geralmente se refere ao estabelecimento de relações sociocomunicativas, como já mencionado. Um exemplo pode ser encontrado em Giddens (2006, p. 1034), onde ele define a interação social como "qualquer forma de encontro social entre indivíduos". Um panorama mais explícito do sociocomunicativo pode ser encontrado na argumentação de Sharma (1996, p. 359) de que "as duas condições básicas da interação social" são "contato social e comunicação". Enquanto pode-se encontrar a dimensão social da definição de interação em conceitos como contato, encontro e reciprocidade (mas, também, em regulação [social]), a dimensão comunicativa é descrita por meio de conceitos tais como resposta, sentido e de comunicação em si.

\section{A participação e o crítico}

Acaso sigamos a rota da abordagem política, o próximo passo é expor as semelhanças entre a abordagem política e a perspectiva crítica, bem como as suas diferenças. Provavelmente, o alinhamento com a perspectiva crítica é conveniente para a abordagem política por duas razões fundamentais. Em primeiro lugar, a abordagem política da participação e a perspectiva crítica compartilham um foco incisivo no poder; e, em segundo lugar, inúmeros autores chave da abordagem política (ex: Arnstein e Pateman, ver mais adiante) também se posicionam dentro da tradição crítica.

Obviamente, antes é necessário explicar aqui o que se entende por "o crítico" $[\ldots]$. Em alguns casos, a teoria crítica é usada de maneira mais restrita, em referência a um grupo de "neo-marxistas insatisfeitos com o estado da teoria marxista" (RITZER, 2008,

\footnotetext{
9 Para fins de melhor coesão, uma referência a outros artigos da edição especial de Javnost - The Public, na qual o artigo foi originalmente publicado, foi removida.
} 
p. 144), mas ainda existem usos mais abrangentes do crítico ${ }^{10}$, que enfocam a mudança social e (portanto) a luta social. Como Calhoun (1995, p. 290) elabora, o crítico "abre mais espaço para se considerar a possibilidade de que o mundo poderia ser diferente do que é [ ... ]". Essa associação íntima com a mudança e a luta torna o crítico sempre ideológico, uma vez que ele utiliza pontos de referência específicos e utopias para se engajar nessas disputas. Esses "não-lugares" e "lugares-que-jamais-serão" concedem ao crítico os seus horizontes máximos, cuja percepção fantasmagórica funciona como um terreno fértil.

Em geral, esses pontos de ancoragem são fornecidos por valores particulares, que quase sempre possuem longas tradições de defesa por determinados grupos e de resistência por outros. Um dos pontos de ancoragem mais frequentemente usados no teoria crítica é o poder, onde a igualdade das relações de poder ou a eliminação de formas de dominação estão no coração do crítico. Por exemplo, Kellner $(1989$, p. 1) resume isso da seguinte maneira: "A teoria crítica é [ ... ] inspirada por uma crítica da dominação e uma teoria da libertação". Em um artigo escrito em parceria, Dahlgren e eu assumimos um posicionamento semelhante quanto ao crítico, expressando uma preferência por definições do crítico que têm "passado a denotar um confronto com restrições desnecessárias e ilegítimas de igualdade, comunidade e liberdades humanas. Em outras palavras, o adjetivo ‘crítico' assinala uma preocupação com discrepâncias problemáticas nas relações de poder em termos normativos" (CARPENTIER \& DAHLGREN, 2013, p. 304).

Isto implica que, ao menos nas abordagens que colocam o poder em primeiro plano, a crítica se torna comprometida com valores como democratização (radical), igualdade e distribuição de poder, os quais apenas fundamentam ainda mais a estreita conexão entre a crítica e a abordagem política da participação. Sobretudo, demonstrar as desigualdades de poder por meio de análises participativas detalhadas permite que se faça uma avaliação crítica, e pode ser considerada como uma condição de possibilidade para uma análise

10 Para distinguir essa abordagem mais abrangente da teoria neo-marxista, a noção de "o crítico" é usada, de maneiras semelhantes, e por razões semelhantes, como Laclau (1996) emprega "o social” ou "o crítico". 
crítica dos processos participativos. Ao mesmo tempo, diante da contundente carga normativa da crítica, cuja presença é uma possibilidade, mas não uma exigência na abordagem política da participação, não deveríamos confundir a crítica e o participativo.

Um exemplo que pode ser usado para ilustrar a relação entre a crítica e o participativo, e o papel central do poder na abordagem política, é A Ladder of Citizen Participation (mencionado anteriormente) de Arnstein (1969). Na introdução do artigo, ela formula a pergunta: " $O$ que é participação cidadã e qual é a sua relação com os imperativos sociais da nossa época?” (1969, p. 216; ênfase no original). A resposta da autora combina a noção de crítica com poder: "A minha resposta à pergunta crítica sobre $o$ que é participação cidadã é que se trata de um termo categórico para poder cidadão" (1969, p. 216; ênfase no original). Arnstein continua:

\begin{abstract}
Ela é a redistribuição de poder que habilita os cidadãos despossuídos, excluídos no presente dos processos políticos e econômicos, a serem incluídos deliberadamente no futuro. É a estratégia pela qual os despossuídos se somam para determinar o modo como a informação é compartilhada, os objetivos e as políticas são instituídas, as verbas públicas são alocadas, os programas são operados e benefícios como contratos e patrocínios são designados. [ ... ] Existe uma diferença crucial entre experimentar o ritual vazio da participação e ter o real poder necessário para afetar o resultado do processo (ARNSTEIN, 1969, p. 216; grifo meu).
\end{abstract}

Arnstein desenvolve uma categorização da participação (a "escada" - ver figura 1), na qual ela distingue três categorias principais (poder cidadão, tokenismo ou inclusão simbólica, não-participação) e oito níveis. A categoria da não-participação consiste de dois níveis: manipulação e terapia. Aqui, o objetivo "não é habilitar as pessoas para que elas participem do planejamento ou condução de programas, mas habilitar autoridades a 'educar' ou 'curar' os participantes" (ARNSTEIN, 1969, p. 217). O tokenismo aqui possui três níveis: informação, consulta e conciliação. Arnstein define a informação como formas de comunicação unilaterais que, apesar da sua importância, ainda permitem poucas oportunidades para que as pessoas influenciem decisões. A consulta é baseada no convite para que as pessoas comuniquem as suas opiniões, mas este nível "ainda é uma farsa porque ele não oferece nenhuma garantia de que as preocupações e ideias dos cidadãos serão levados em consideração" (1969, p. 219). A conciliação é vista como um nível mais elevado de tokenismo pelo qual uma seleção de despossuídos pode aconselhar, mas as autoridades ainda detém o direito de decidir. A última categoria (maximalista) é poder cidadão, que possui três níveis: parceria, poder delegado e controle cidadão. No 
caso da parceria, as responsabilidades dos cidadãos e das autoridades são compartilhadas por meio de "conselhos comuns de políticas públicas, comitês de planejamento e mecanismos para solucionar impasses" (1969, p. 221). No caso do poder delegado, os cidadãos adquirem a predominância como autoridade na tomada de decisão em um plano ou programa particular. Finalmente, o controle cidadão expande ainda mais a posição de poder dos cidadãos, embora Arnstein alerte quanto à crença numa situação de controle total.

\section{Um modelo analítico para escolher o caminho mais difícil - além da escada} Por mais relevantes que esses modelos (mais antigos) sejam para demonstrar o alinhamento da crítica com a participação, e a importância do poder para as análises participativas, os modelos baseados na escada também apresentam uma série de problemas (cuja maioria é reconhecida por Arnstein [1969, p. 217]).

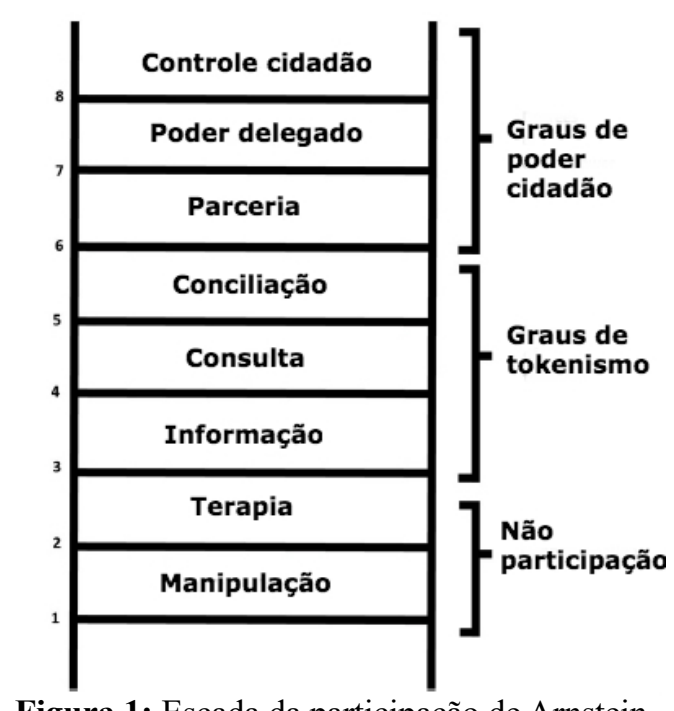

Figura 1: Escada da participação de Arnstein Fonte: Arnstein (1969, p. 217)

Com bastante frequência, esses modelos sugerem a existência de limiares simples entre as posições dicotomizadas. Mesmo quando se distingue vários degraus, esses modelos discretos ainda sugerem categorizações cruas demais (ex: poder cidadão $\mathrm{X}$ tokenismo e não-participação) que nem sempre correspondem bem às complexidades dos processos participativos. Em segundo lugar, o caráter multifacetado dos processos participativos também dificulta a sua captura pelas abordagens baseadas na escada. As 
intensidades participativas podem mudar ao longo do tempo, mas diversos componentes em um único processo às vezes também podem produzir diferenças. Na sua discussão sobre as éticas participativas (abertas), Ward (2011) explica como a participação em um processo específico pode ser intensa em um componente, mas mínima em outro. Por exemplo, éticas participativas (abertas) poderiam ser abertas na discussão de novas orientações éticas, mas não na sua adoção formal. Geralmente, Ward (2011, p. 227) argumenta que nós "apenas alcançamos um juízo grosseiro e comparativo", especialmente quando "existem forças que se movem em direções opostas". Tomemos como exemplo o YouTube, que permite a participação na publicação de vídeos, mas não na administração do próprio YouTube. Para citar Jenkins (in JENKINS \& CARPENTIER 2013, p. 275) quanto a este assunto: há "limites para a nossa capacidade de participar no YouTube - a ponto dos participantes não exercerem qualquer interferência direta na governança da plataforma. Isso é muito diferente de discutir como as comunidades participativas usam o YouTube como um canal de distribuição”. Em terceiro lugar, as abordagens baseadas na escada tendem a ver a participação como um resultado estável de um processo, ignorando as disputas por intensidades participativas nesses processos, em campos particulares e na sociedade. Atores diferentes podem ter perspectivas e interesses diferentes, e desenvolverão estratégias diferentes para ver as suas perspectivas reconhecidas, entrando em conflito uns com os outros. Provavelmente, isso gera um processo muito mais dinâmico e contigente (ou instável) do que as abordagens baseadas na escada aparentam indicar. Em quarto lugar, existe a relação já discutida entre o participativo e a crítica. Um dos problemas com as abordagens baseadas na escada é que elas confundem o participativo e a crítica, levando longe demais o alinhamento existente entre essas duas noções, o que transforma a escada da participação em uma escadaria para o paraíso (político-democrático). Em quinto lugar, nas abordagens baseadas na escada, apesar do enfoque no poder, a noção de poder frequentemente se torna hermética ou pouco teorizada. Uma estrutura teórica mais robusta não só permite abordar os problemas da contingência, do caráter multifacetado e da complexidade que acabaram de ser mencionados, mas também sustenta uma análise mais sofisticada das disputas materiais e discursivas que são uma parte intrínseca das dinâmicas de poder (em particular quando se usa um modelo estratégico/foucaultiano - ver mais tarde). No contexto da análise 
participativa, é crucial ganhar um melhor entendimento sobre os diferentes aspectos do poder para uma compreensão maior dos processos participativos e suas muitas dimensões.

Superar o modelo baseado na escada, sem abandonar a abordagem política, para pesquisar processos participativos acarreta uma série de desafios. Se ainda se considera a participação como referente à equalização das relações de poder entre atores privilegiados e não-privilegiados, em processos de tomada de decisão formais ou informais, em um contexto particular, consequentemente, esta escolha requer que esses processos (e subprocessos ou micro-processos), contextos, atores, decisões e relações de poder sejam teorizados e definidos para só então serem analisados. A abundância de conceitos envolvidos (e invocados) nos processos participativos produz um nível de complexidade analítica que é difícil de lidar, mesmo da perspectiva do pesquisador. Esta parte tenta deslindar esta complexidade, desenvolvendo um modelo analítico de quatro níveis que posiciona os conceitos teóricos e analíticos tão distintos e, assim, pode funcionar como um guia para a pesquisa participativa que aplica a abordagem política.

\section{O processo e seu (s) campo (s)}

O ponto de partida do modelo analítico é identificar o processo midiático particular cuja natureza participativa será investigada, assim como os objetivos desse processo (primeira etapa). A noção de processo se refere a uma série de atividades com objetivos relacionadas entre si, o que é similar às maneira como esse conceito é definido na teoria organizacional (e no marketing). Por exemplo, Juran (2003, p. 358) define processo como "uma série sistemática de ações dirigidas ao cumprimento de um objetivo", enquanto Cummings \& Worley (2014, p. 790) percebem o processo como "o modo pelo qual as pessoas se relacionam entre si quando desempenham alguma atividade". Sem corroborar com os princípios básicos da teoria dos sistemas, deve-se notar que, na teoria organizacional, a teoria dos sistemas é usada geralmente para definir processo - como, por exemplo, fazem Hammer \& Champy (1993, p. 53) ao definir processo como "uma coleção de atividades que depende de um ou mais tipos de contribuição (input) e produz um resultado (output) [ ... ]".

A noção de processo é importante aqui, porque ela permite restringir o objeto de análise a um processo particular que pode ser definido, delineado e analisado. Na teoria 
participativa, com demasiada frequência, podemos encontrar afirmações genéricas sobre a condição participativa de uma nação, região ou do mundo que são difíceis de substanciar por meio de pesquisa. Por essa razão, a noção de processo funciona como uma força protetora contra argumentos ambiciosos demais e obriga os pesquisadores a manterem os pés no chão. Sobretudo, a noção de processo também permite incluir a ideia de que a participação é sempre localizada em processos particulares, com altos níveis de complexidade (em geral), que requerem análise minuciosa.

Ao mesmo tempo, os processos se situam em contextos invariavelmente particulares que também afetam a sua natureza e desenvolvimento. Aqui, ao menos em parte, eu gostaria de usar a teoria de campo de Bourdieu, já que a noção de campo indica a existência de domínios ou espaços que possuem uma autonomia relativa, alimentados pelos conhecimentos e interesses particulares dos seus atores. Como elabora Bourdieu,

\begin{abstract}
Um campo [ ... ] se define (entre outras coisas) pela definição de apostas e interesses específicos, os quais são irreconciliáveis com as apostas e interesses específicos de outros campos [...] e que não são percebidos por quem não foi moldado para entrar naquele campo [ ... ]. Para que um campo funcione, é preciso haver apostas e pessoas preparadas para jogar o jogo [ ... ] (Bourdieu, 1993, p. 72).
\end{abstract}

Para Bourdieu (1993, p. 73; ênfase no original), o poder desempenha um papel importante, pois a "estrutura do campo é um estado de relações de poder entre os agentes ou instituições engajados na disputa [ ... ]". A participação não se limita a um campo societal específico (ex: “a” economia ou "a" política), mas está presente em todos os campos societais. Podemos encontrar processos participativos na política - afinal de contas, as democracias representativas se baseiam na existência (de um grau) de participação - mas também no campo econômico, no campo cultural, no campo da família e no campo midiático (entre muitos outros campos). Simultaneamente, o que esses diferentes campos somam à equação são cruciais para a nossa compreensão de qualquer processo participativo. Cada campo tem as suas próprias políticas, economias, culturas, relações sociais e estruturas comunicacionais. Analisar as características básicas do campo (segunda etapa), como ele é construído e estruturado, com que saberes, posições, interesses, apostas, mercadorias e histórias, além de que relações exatamente entre o processo participativo e o campo são organizadas (terceiro passo), portanto, tornam-se inevitáveis. 
É preciso levar em conta uma complexidade, porque deveríamos reconhecer a existência da participação transcampo: em alguns casos, um processo particular em um campo facilita a participação em outro. Por exemplo, um projeto de arte urbana pode oferecer pouca participação no mundo da arte em si, mas pode oferecer níveis consideráveis de participação no ambiente urbano, como evidenciado pelos projetos Body Movies de Rafael Lozano-Hemmer ${ }^{11}$. Ou a participação do leitor na empresa jornalística, que pode ser rara e limitada (com algumas notáveis exceções), porém, com esse mecanismo, os jornais permitem que os leitores intervenham (em algum grau) no campo político. Para entender melhor essas formas de participação transcampo, podemos recorrer a Wasko \& Mosco (1992, p. 7), que elaboram uma distinção entre a democratização da mídia e a democratização através da mídia, de modo que possamos distinguir entre participação em um campo particular, e participação por meio de um campo particular em outro campo. Existem o que eu sugiro chamar de formas transgressoras de participação (onde o processo participativo transgride as fronteiras de um campo particular e se situa em diversos campos) e formas transferidas de participação (onde um processo não-participativo em um campo particular permite a participação em outro campo), o que pode requerer a incorporação de diversos campos na análise.

\section{Os atores}

Uma vez selecionado o processo, e a sua posição no campo ou campos relevantes tenha sido analisada, pode-se voltar a atenção para os atores que se envolveram no processo a ser estudado. Por ser uma noção sociológica, o ator incorpora tanto os seres humanos individuais quanto os atores sociais ${ }^{12}$ — o que Harré (1981, p. 141ff) chamou de supra-indivíduos. Esses atores sociais “organizacionais” podem assumir muitas formas e, aqui, a lista de exemplos de Sibeon (2004, p. 119) ajuda a demonstrar a riqueza dessa categoria: "comitês, famílias, pequenos grupos e, principalmente, organizações dos setores estatal, privado ou voluntário, incluindo grupos de interesse, partidos políticos, universidades, sindicatos, associações profissionais, empresas privadas, órgãos federais,

\footnotetext{
11 Disponível em: < http://www.lozano-hemmer.com/body_movies.php> Acesso em:18 Dez. 2015. 12 A Teoria Ator-Rede também incluiria objetos nessa lista. No contexto deste artigo, preferiu-se não fazê-lo, já que a discussão sobre a possibilidade de participação dos poderia nos desviar demais do objetivo do artigo.
} 
autoridades locais e daí em diante". Ao mesmo tempo, embora deva-se evitar a reificação, deve-se reconhecer que os atores sociais possuem estruturas de tomada de decisão e indução de ação, o que permite que eles funcionem como entidades (ideais) particulares no plano social. Assim, isso nos leva à definição de ator cunhada por Hindess (1986, p. 115) como "um locus de decisão e ação, onde a ação é, em certo sentido, uma consequência das decisões do ator".

O segundo nível do modelo analítico enfoca esses atores. Primeiro, todos os atores (humanos e sociais) envolvidos no processo participativo precisam ser identificados e as suas relações devem ser mapeadas (quarto passo). Por exemplo, no caso de um programa televisivo com debate da audiência, isso implicaria identificar os diferentes profissionais e administradores da mídia, suas produções e emissoras (e seus fornecedores), os especialistas convidados, celebridades e gente comum, a platéia do estúdio, e daí em diante. Os rótulos usados no exemplo imediatamente nos guiam para o próximo passo, que consiste da análise das posições materiais, identidades e papéis dos atores envolvidos (quinto passo). Essas posições materiais, identidades e papéis importam porque elas desempenham um papel estruturante no processo participativo. As posições materiais, por exemplo, baseiam-se no acesso a determinados recursos, tais como os diferentes tipos de capital. Essas posições materiais fazem parte de um nó discursivo-material; elas são atadas às estruturas de sentido das identidades, um conceito que é abordado neste artigo de uma perspectiva mais sócio-cultural. Isso permite definir identidade como o posicionamento dos sujeitos em uma estrutura discursiva (LACLAU \& MOUFFE, 1985, p. 115). Por sua vez, os papéis passam a ser vistos como traduções dessas identidades sob a forma de comportamento ideal e real. A teoria do discurso de Laclau e Mouffe também permite enfatizar que as identidades (ou posições do sujeito, como Laclau \& Mouffe as denominam) não são necessariamente estáveis, porque elas podem ser objetos de disputas discursivas e tentativas de rearticulação. Ao mesmo tempo, essas identidades são estabilizadas por meio de práticas hegemônicas, que criam versões mais rígidas dessas identidades.

Em segundo lugar, assim como os atores não são dominados pelas estruturas materiais, eles tampouco são dominados por estruturas discursivas, já que essas estruturas constroem, numa base individual ou coletiva, identificações sempre particulares com 
essas identidades, as quais produzem individualidade e liberdade ${ }^{13}$. Aqui, também, devemos ser cuidadosos com a equação de identidades e identificações, pois isso implicaria a reificação dessas identidades.

Por exemplo, e enfocando a identidade: no caso do profissional da mídia (como argumentado anteriormente, ver CARPENTIER, 2013), a valiosa lista de características desses profissionais compilada por McQuail (2008, p. 53) (mas também o trabalho mais focado nos profissionais da mídia; DEUZE, 2005; CARPENTIER, 2005) pode ser usada para distinguir uma série de elementos que constroem a posição do sujeito do profissional da mídia (modernista), numa relação oposta ou às vezes antagônica com a identidade da audiência. Aqui, o argumento é que a identidade de um profissional da mídia consiste de uma série de blocos de montar que, operando juntos, constroem essa identidade: a noção de expertise, adquirida por meio de treinamento e educação; o serviço público que é proporcionado tanto para audiências específicas quanto para a sociedade em geral; o conceito de ética, que, em contrapartida, vincula-se às noções de verdade, imparcialidade, autenticidade, integridade e honestidade; a um certo grau de autonomia; a integração institucional; e o emprego de gerenciamento e poder. Os argumentos da contingência e identificação, claro, devem ser reiterados: a identidade do profissional de mídia descrito aqui é a versão dominante tradicional, e existem muitas rearticulações - por vezes bem sucedidas, por outras, não (ver CARPENTIER, 2005). Sobretudo, determinados profissionais de mídia se identificarão com essas identidades de maneiras diferentes, aceitando algumas partes, mudando outras partes e ainda rejeitando outras partes. Compreender como essas identidades e identificações funcionam no processo participativo é altamente instrumental e necessário.

$\mathrm{Na}$ última etapa desse segundo nível, deve-se analisar as posições dos atores no campo para ver se essas posições são privilegiadas no campo (na sua parte hegemônica) ou não (sexta etapa). Aqui, é importante enfatizar que este passo se relaciona com a posição societal geral dos atores, e não com a posição dos atores no processo participativo particular. A lógica deste passo corresponde à ideia de que a participação é sempre e necessariamente corretiva: um processo participativo corrige um desequilíbrio societal de 
poder mais geral, onde atores que têm posições de poder diferentes na sociedade entram em um processo onde esse desequilíbrio de poder é (parcialmente) abordado e equalizado. Como conceito, participação não se aplica a situações nas quais os atores que têm posições de poder equânimes interagem e co-decidem. Para ilustrar, o dono de uma empresa midiática que toma parte em uma reunião de donos de empresas midiáticas não está envolvido em um processo participativo. Um representante dos funcionários da empresa midiática presente na mesma reunião - e, muito provavelmente, sentindo-se em uma relação de poder diferente daquela dos proprietários de empresas midiáticas - ao ser envolvido no processo de tomada de decisão, está, de fato, participando. Um argumento semelhante pode ser encontrado na teoria democrática, onde sempre existe um equilíbrio entre participação e representação na democracia (HELD, 1996). Os líderes políticos (como parte do governo e parlamento) possuem uma posição privilegiada na sociedade, uma vez que os poderes para a tomada de decisão lhes são delegados, que é o princípio da representação (política). Ao mesmo tempo, o desequilíbrio de poder criado por essa situação é corrigido pelos processos participativos (como as eleições) para compensar esse desequilíbrio de poder e elevar a posição de poder das pessoas que são governadas por essas elites políticas.

Outra maneira de esclarecer essa noção de privilégio é referir-se a elites societais e não-elites, embora seja necessário ter cuidado para não definir todos os atores privilegiados como parte de uma elite societal. Esta é uma questão que Arnstein (1969, p. 217) já havia levantado quando escreveu: "na atualidade, nem os despossuídos tampouco as autoridades formam blocos homogêneos". Ao mesmo tempo, esses atores privilegiados formam agregados de elite (parcialmente superpostas) que exercem as posições de poder mais fortes em comparação com os indivíduos que não fazem parte desses agregados de elite. Analisar se atores são privilegiados no campo (novamente, em geral), e outros, não, permite categorizar os atores em grupos e identificar os agregados de (não) elite aos quais eles pertencem (sem misturar todos os atores [não-]privilegiados em uma categoria de [não-]elite). Após identificar grupos e agregados (ex: profissionais da mídia, políticos, especialistas, pessoas comuns, artistas) é um passo necessário para analisar e comparar as decisões tomadas por esses grupos/agregados de atores (terceiro nível) e, no final, as suas posições de poder (quarto nível). 


\section{As decisões}

Antes de mais nada, o terceiro nível do modelo analítico demarca todos os momentos do processo participativo e a sua importância em relações aos objetivos do processo participativo (sétima etapa). Novamente, esta etapa requer que se defina o conceito-chave (a decisão), o que não é muito simples. Nesse caso, eu gostaria de seguir a definição de Laclau \& Mouffe para decisão, como um momento de fixação ${ }^{14}$. É isso que transforma a decisão em um processo político como elabora Mouffe (2000, p. 130) na sua convocação a uma “reflexão apropriada sobre o momento da ‘decisão' com características do campo da política". A essa ideia, ela acrescenta que a decisão - como um momento de fixação - inclui "um componente de força e violência" (2000, p. 130). Outra maneira de entender isso é por meio da metáfora (mais materialista) da máquina de Deleuze e Guattari, "um sistema de interrupções ou rupturas" que "está relacionada com um fluxo material contínuo [...] que ela corta" (1984, p. 36; ênfase removida). Para Laclau, a decisão é o momento que captura o fluxo contínuo, conduzindo-o a uma suspensão (temporal) e estruturando-o de um modo particular. Isso também implica que as decisões são momentos nas quais o poder é exercido (ou não), por exemplo, como alguns dos autores chave das teorias do poder tem argumentado (BACHRACH \& BARATZ, 1962; LUKES, 1984).

A análise dos momentos de tomada de decisão, como micro-processos do processo participativo principal, é complicada pela sua grande quantidade mas, também, pela sua natureza diversa, já que as decisões podem ser planejadas ou não planejadas, formais ou informais, explícitas ou implícitas, de curto prazo ou longo prazo, gerais ou particulares, limitadas no tempo ou não, únicas ou combinadas, estratégicas, táticas ou operacionais, e daí em diante. Por causa dessas razões, tentativas de construir categorizações ou tipologias gerais são altamente propensas a fracassar. Mesmo assim, pode-se mencionar inúmeras áreas no campo da produção midiática, mantendo em mente que se trata de uma lista interminável, e que áreas de tomada de decisão precisam ser geradas por meio da

14 Obviamente, também existem definições menos abstratas disponíveis; como, por exemplo, a definição de Harrison (1987, p. 2) para decisão como "um momento em um processo em andamento quando são avaliadas alternativas para atingir um objetivo, durante o qual as expectativas quanto a um determinado rumo da ação estimula quem tomará a decisão a escolher o curso da ação mais propenso a resultar no alcance do objetivo". 
própria análise. No nível do acesso, as decisões são tomadas por quem tem acesso ao processo participativo (e quem não tem), além de quem tem acesso aos espaços e lugares, infraestruturas, tecnologias, atores, Informação, recursos financeiros e daí em diante. No nível da interação, decide-se quem tem autorização para produzir conteúdo e sob que condições, quanto à aquisição ou aperfeiçoamento de habilidades e conhecimento, quem pode representar a si mesmo ou a outros, e de que forma, quanto ao modo como os processos são classificados e quem pode interagir com quem. No nível da participação em si, podemos enumerar uma série de decisões igualmente relevantes: quanto a quem decide sobre os enquadramentos regulatórios que estruturam as ações das pessoas, quanto aos procedimentos e objetivos das próprias tomadas de decisão e quanto à sua implementação.

Uma vez que os momentos de tomada de decisão tenham sido identificados, podemos observá-los melhor nas ações dos diferentes atores (e seus grupos/agregados) durante esses momentos de decisão, e nas relações com as suas posições materiais, identidades e papel (oitava etapa). As perguntas estruturantes para esta etapa parecem simples: quem faz o que nos diferentes momentos de decisão, e como eles se relacionam e são amparados pelas posições materiais, identidades e papéis? Mais uma vez, o mapeamento das práticas materiais e discursivas de todos os atores que fazem parte de um processo participativo envolve uma complexidade excessiva, mesmo quando o foco se volta para os momentos de tomada de decisão. Esta complexidade é causada pela diversidade de ações possíveis, nas quais cada momento de tomada de decisão pode incorporar uma ampla variedade de ações, desde a aceitação passiva e silenciosa de uma decisão, a resistência quanto a decisões tomadas por outros, até práticas ativas e coletivas de tomada de decisão. Uma complexidade adicional é causada pela infinidade de relações possíveis entre ações, posições materiais, papéis, identidades e identificações. Contudo, permanece importante ver como o emprego de ações particulares está intimamente associado ao modo como determinadas identidades são interpretadas e usadas pelos atores em condições de equilíbrio. 


\section{Relações de poder}

No quarto e último nível do modelo analítico, a atenção enfim se volta para a análise das relações de poder. Para fundamentar esta análise, é necessária uma reflexão aprofundada sobre o poder, que só pode ser representado neste artigo de modo muito superficial. Para abordar os aspectos contingentes, multiface e complexos dos processos participativos, dá-se preferência ao modelo do poder estratégico/foucaultiano (FOUCAULT, 1978). Neste modelo, nós afastamos a ideia de poder como propriedade, sem ignorar a natureza não-igualitária das relações de poder. A resistência também é vista como parte de um exercício contingente de poder (KENDALL \& WICKHAM, 1999, p. 50). Como, por mais privilegiado que seja, nenhum ator pode exercer um controle total e irrestrito sobre o social, e as posições mais dominantes geralmente geram resistência, o modelo estratégico/foucaultiano permite que vejamos uma multiplicidade de estratégias que formam um complexo jogo de poder. Um meio de tornar este modelo de poder ainda mais operacional é usar a dialética do controle de Giddens (1979, p. 91), na qual ele distingue entre a capacidade transformadora do poder - tratar o poder em termos de conduta de agentes que exercitam o livre-arbítrio - de um lado e, de outro, a dominação - tratar o poder como uma qualidade estrutural. O componente restritivo se alinha muito bem com a percepção de Foucault de que as relações de poder podem ser desequilibradas, enquanto o componente generativo se refere aos objetivos e conquistas das estratégias sobre as quais Foucault elabora a sua analítica do poder. A resistência intervém tanto sobre os componentes restritivo e generativo do poder, e, portanto, pode ser considerada o terceiro componente desse modelo de poder. Consequentemente, o efeito geral das estratégias restritivas, generativas e de resistência passa a ser classificado como a dimensão produtiva do poder. Retornando ao nosso modelo analítico para o processo participativo: esse modelo de poder é usado para desempenhar uma análise de poder do material coletado nos três níveis anteriores (e, particularmente, no terceiro nível).

A nona etapa aplica as distinções entre os aspectos generativo, restritivo e resistente do poder a cada momento de tomada de decisão, permanecendo o foco desses microprocessos de participação (potencial). As questões que surgem aqui: o que cada ator gera e o que é gerado para eles, o que é restringido para cada ator e o que eles restringem, e que ações (de qual ator) sofrem resistência por quais outros atores? A pergunta 


\section{míDiA

estruturante por trás desse conjunto de indagações é: quem decide o quê? (ver CARPENTIER [2001] para uma discussão extensa sobre um exemplo chamado Jan Publiek). Enquanto um grupo de atores privilegiados, os profissionais da mídia decidem sobre este ponto, ou consultam e permitem que o painel de participantes comuns, enquanto atores não-privilegiados, co-decidam? Os participantes comuns resistem e tentam influenciar esta decisão, e a sua capacidade de fazê-lo é restringida pelos profissionais da mídia?

Logo que esses micro-processos de poder no processo participativo principal tenham sido analisados, é preciso aplicar uma estratégia adicional, que consiste da comparação entre as posições de poder dos atores (e seus grupos/agregados), mais uma vez enfocando, principalmente, as posições de poder dos atores privilegiados e nãoprivilegiados, mas agora ao longo de todo o processo participativo (décima primeira etapa). A pergunta estruturante é: o quanto as relações de poder são equilibradas durante todo o processo participativo? Esta etapa pode resultar, por exemplo, na identificação de um desequilíbrio de poder generalizado, ou na identificação de áreas particulares de compartilhamento de poder, enquanto outras decisões são tomadas por atores privilegiados (os quais podemos classificar como “zonas participativas”), onde estas áreas podem, ou não, ser relevantes ao longo de todo o processo. Outros desdobramentos se tornam possíveis por meio de um conjunto equilibrado de relações de poder, ou uma combinação muito dispersa de equilíbrios e desequilíbrios de poder. $\mathrm{Na}$ última etapa do modelo analítico, o agregado de equilíbrios e desequilíbrios de poder de todo o processo participativo precisa ser avaliado (décima segunda etapa). 

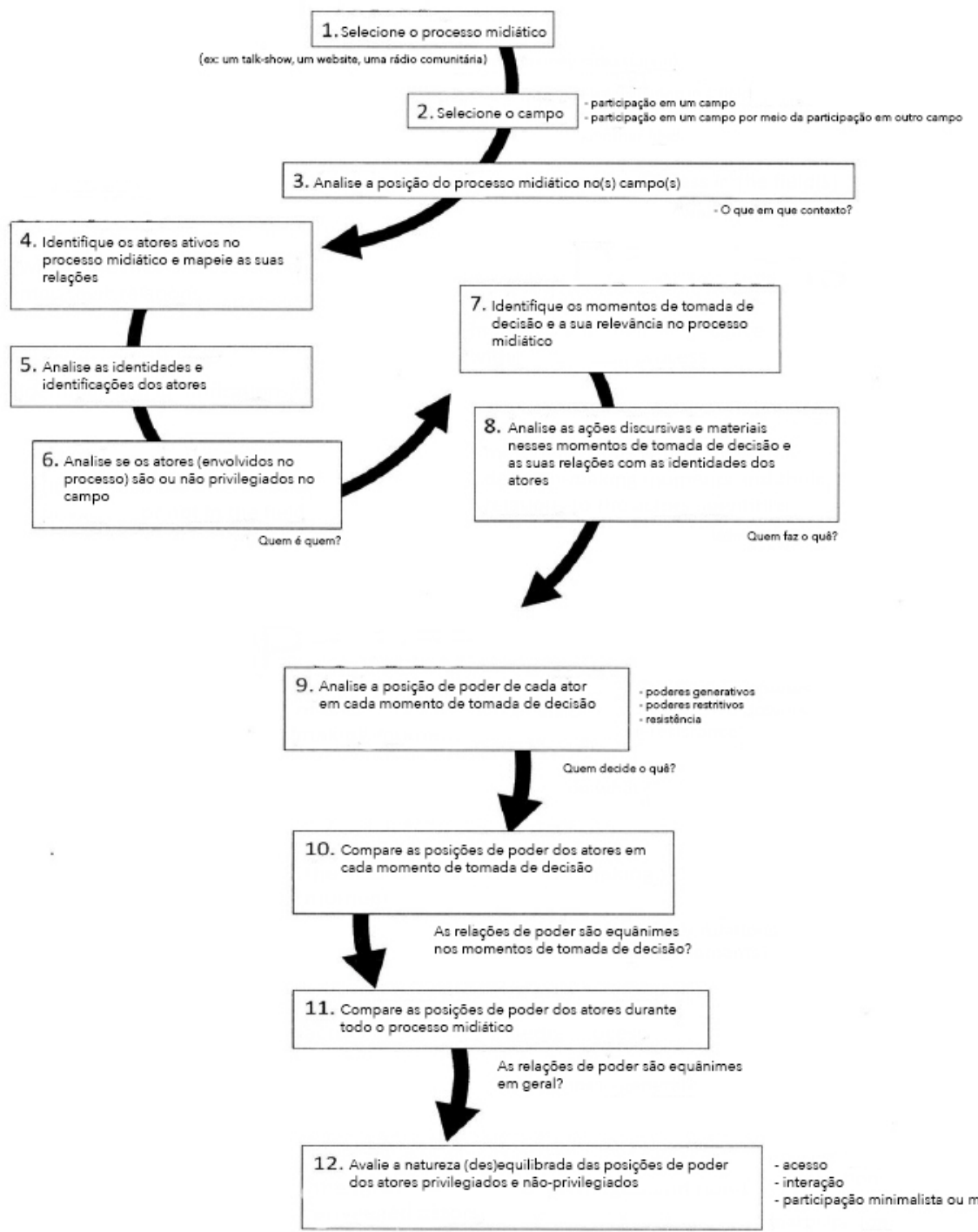

Figura 2: Um modelo analítico para o estudo dos processos midiáticos participativos sob a perspectiva da abordagem política

Isso nos leva de volta à dimensão foucaultiana do poder produtivo e do efeito geral: que tipo de participação está sendo produzida no processo participativo observado? Para esta avaliação, em primeiro lugar, pode-se empregar a distinção entre acesso, interação e participação. Isso nos leva de volta à ideia básica da abordagem política, segundo a qual a participação é vista como compartilhamento de poder, sem limitar a participação a simplesmente tomar parte em um processo (o que é típico da abordagem sociológica). 
Para avaliar a natureza participativa de um processo, é necessário indagar se existe qualquer partilha de poder afinal. Em alguns casos, seguindo atentamente as abordagens baseadas na escada, precisamos reconhecer que um processo classificado como participativo simplesmente não é aquilo que diz ser. Porém, uma vez que a existência de níveis particulares de compartilhamento de poder tenha sido estabelecida, deve-se fazer a pergunta sobre a intensidade participativa. A dimensão da participação minimalista e maximalista é uma ferramenta útil para estabelecer intensidades participativas, considerando que, nas formas mais minimalistas de participação midiática, os profissionais da mídia detém forte controle sobre o processo e o resultado, enquanto nas formas maximalistas as relações de poder dos profissionais da mídia e os grupos nãoprivilegiados são equilibradas. $\mathrm{Na}$ avaliação dessas intensidades participativas continua importante integrar as críticas das abordagens baseadas na escada, além de prestar atenção às contingências (ex: espaço e tempo), nas camadas múltiplas e complexidades da participação, o que resulta em avaliações mais qualificadas da intensidade participativa de um processo em particular. A Figura 2 fornece um panorama do modelo analítico, representando os quatro níveis e as doze etapas para estudar os processos participativos (midiáticos) a partir da abordagem política.

\section{Conclusão}

Embora a abordagem sociológica tenha os seus méritos, este artigo defende o uso de uma noção mais restritiva da noção de participação. Isso não implica que é irrelevante estudar a interação social (mediada), que é o que a abordagem sociológica faz - caso aceitemos o vocabulário da abordagem política - e tampouco que isso signifique que a interação social, enquanto processo societal, seja menos relevante do que a participação.

O que a abordagem política argumenta é que, em relação a determinadas tomadas de decisão, a lógica do poder importa e que esse componente do social é suficientemente relevante para ser distinguido da interação social, e para ser designado por um termo próprio. Dado o enfoque das tradições da teoria política (e, em particular, da teoria democrática) na tomada de decisão e no poder, participação é o termo óbvio empregado aqui. 


\section{miDiA

O que este artigo demonstrou, também, é a complexidade dos processos participativos, que sequer as já sofisticadas abordagens baseadas na escada têm conseguido capturar satisfatoriamente. Sobretudo, muitas das abordagens políticas da participação se esquivaram da tradução dos seus postulados teóricos em um modelo analítico. Uma vez que se abra essa caixa-preta, torna-se claro que os muitos conceitos teóricos à deriva precisam encontrar o seu lugar, e que existe uma necessidade de estruturar (analiticamente) e priorizar o imenso nível de detalhe por meio de certos conceitos-chave. Neste modelo analítico, escolheu-se processo, campo, ator, momento de tomada de decisão e poder. Ao mesmo tempo, é necessário manter um alto grau de abertura analítica (e metodológica) em relação à complexidade dos processos participativos para evitar que a visão do analista seja ofuscada por um determinado (sub)processo, evitando, ainda, que as contingências e contradições onipresentes sejam excluídas pelo bem da elegância analítica.

Finalmente, isso nos leva de volta à crítica. Em virtude do interesse e vocabulário comuns, o enfoque na divisão societal de poder e na existência dos equilíbrios e desequilíbrios de poder se alinha bem com a perspectiva crítica. Porém, simultaneamente, deveria-se enfatizar que, por causa das suas diferenças quanto à normatividade, a abordagem política da participação e a perspectiva crítica permanecem distintas. A abordagem política da participação visa analisar os níveis de igualdade (de poder) nos processos participativos, e isso termina no momento em que a crítica pode começar por meio da análise da intensidade dos processos participativos; ou, em outras palavras, do quanto equânimes ou desiguais eles são. A perspectiva crítica pode - caso se deseje acrescentar uma última décima terceira camada normativa à análise, por meio da avaliação do anseio societal por essas relações de poder equânimes ou desiguais. Se a conclusão da análise participativa é que um determinado processo é minimalista, então diferentes avaliações normativas ainda são possíveis. Pode-se, por exemplo, alegar que a natureza minimalista do processo participativo é apropriada e desejável, ou criticá-la por ser "apenas" minimalista. Pode-se resolver essa questão revertendo-se ao normativo, e, aqui, à crítica - com a sua ênfase na mudança social por meio de níveis mais altos de compartilhamento de poder - funciona como um ponto de referência para permitir essa avaliação. Embora eu mesmo não me sinta confortável com o acréscimo desta última 
camada, e em defesa de uma sociedade mais igualitária, trata-se não de uma exigência da abordagem política da participação em si, mas de uma escolha.

\section{Declaração Informativa:}

Nenhum conflito de interesses em potencial foi relatado pelo autor.

\section{Financiamento:}

Esta pesquisa foi realizada com auxílio de uma bolsa sabática do Conselho de Pesquisa da Vrije Universiteit Brussel e por uma bolsa de pesquisa (código G016114N) concedida pelo Fonds Wetenschappelijk Onderzoek - Vlaanderen (FWO).

\section{Referências}

ALLEN, Danielle; BAILEY, Moya; CARPENTIER, Nico; FENTON, Natalie; JENKINS, Henry; LOTHIAN, Alexis; QUI, Jack Linchuan; SCHAEFER, Mirko Tobias \& SRINIVASAN, Ramesh. Participations: Dialogues on the Participatory Promise of Contemporary Culture and Politics. Part 3: Politics. International Journal of Communication, n. 8, pp. Forum 11291151. Acesso em:18 Dez. 2015. Disíponvel em:

$<$ http://ijoc.org/index.php/ijoc/article/view/2787/1124>.

ARNSTEIN, Sherry R. A Ladder of Citizen Participation. Journal of the American Institute of Planners, n. 35, v. 4, pp. 216-224, 1969.

BACHRACH, Peter \& BARATZ, Morton S. The Two Faces of Power. American Political Science Review, n. 56, pp. 947-952, 1962.

BOURDIEU, Pierre. Sociology in Question. Londres: Sage, 1993.

BRADDOCK, Chris. Performing Contagious Bodies: Ritual Participation in Contemporary Art. Londres: Palgrave Macmillan, 2009.

BUNGE, Mario A. Treatise on Basic Philosophy: Volume 3: Ontology I: The Furniture of the World. Berlin: Springer, 1977.

CAREY, James W. Communication as Culture. Essays on Media and Society. Edição Revisada. Nova Iorque: Routledge, 2009.

CALHOUN, Craig. Critical Social Theory: Culture, History, and the Challenge of Difference. Cambridge: Wiley-Blackwell, 1995.

CARPENTIER, Nico. Managing Audience Participation. European Journal of Communication, n. 16, v. 2, pp. 209-232, 2001. 
. Identity, Contingency and Rigidity. The (Counter-)Hegemonic

Constructions of the Identity of the Media Professional. Journalism, n. 6, v. 2, pp. 199-219, 2005.

Bristol: Intellect., 2011.

. Media and Participation: A Site of Ideological-Democratic Struggle.

. The Identity Constructions of Media Professionals. Coping with Modernist Articulations of the Media Professional as Author and the Recognition of Difference. In: MERTENS, Stefan (org.). Perspectieven op Internationale Journalistiek [Perspectives on International Journalism], pp. 5-18. Gent: Academia Press, 2013.

\& DAHLGREN, Peter. The Social Relevance of Participatory Theory. Comunicazioni Sociali, n. 3, pp. 301-315, 2013.

; DAHLGREN, Peter \& PASQUALI, Francesca. The Democratic (Media) Revolution: A Parallel History of Political and Media Participation. In: CARPENTIER, Nico; SCHRØDER, Kim \& HALLET, Lawrie (org.). Audience Transformations: Shifting Audience Positions in Late Modernity, pp. 123-141. Londres: Routledge. 2014.

CUMMINGS, Thomas \& WORLEY, Christopher. Organization Development and Change. $10^{\mathrm{a}}$ ed., Stamford: Cengage Learning, 2014.

DAHLGREN, Peter. Media and Political Engagement. Nova Iorque: Cambridge University Press, 2009

The Political Web. Basingstoke: Palgrave Macmillan, 2013.

DAYAN, Daniel \& KATZ, Elihu. Media Events: The Live Broadcasting of History.

Cambridge, MA: Harvard University Press, 2009.

DELANEY, Tim \& MADIGAN, Tim. The Sociology of Sports: An Introduction. Jefferson, NC: McFarland, 2009.

DELEUZE, Gilles \& GUATTARI, Felix. Anti-Oedipus: Capitalism and Schizophrenia. Londres: Athlone Press, 1984.

DEUZE, Mark. What is Journalism? Professional Identity and Ideology of Journalists. Journalism, n. 6, v. 4, pp. 442-464, 2005.

FIERLBECK, Katherine. Globalizing Democracy. Power, Legitimacy and the Interpretation of Democratic Ideas. Manchester: Manchester University Press, 1998.

FOUCAULT, Michel. History of Sexuality: Part 1. An Introduction. Nova Iorque: Pantheon, 1978.

GIDDENS, Anthony. Central Problems in Social Theory: Action, Structure and

Contradiction in Social Analysis. Londres: Macmillan, 1979.

Profile, 2002.

. Runaway World: How Globalisation is Reshaping our Lives. Londres:

. Sociology. $5^{\text {a }}$ ed. Cambridge: Polity Press, 2006. 
HAMMER, Michael \& CHAMPY, James. Reengineering the Corporation: A Manifesto for Business Revolution. Nova Iorque: Harper Business, 1993.

HARRÉ, Rom. Philosophical Aspects of the Macro-Micro Problem. In: KNORR-CETINA, Karin \& CICOUREL, Aaron V. (org.). Advances in Social Theory and Methodology: Towards an Integration of Micro- and Macro Sociologies, pp. 139-160. Londres: Routledge, 1981.

HARRISON, E. Frank. The Managerial Decision-making Process. Boston: Houghton-Mifflin, 1987.

HELD, David. Models of Democracy. $2^{\mathrm{a}}$ ed. Cambridge e Stanford, CA: Polity Press e Stanford University Press, 1996.

HINDESS, Barry. Actors and Social Relations. In: WARDELL, M. L. \& TURNER, S. P. (org.). Sociological Theory in Transition, pp. 113-126. Londres: Allen \& Unwin, 1986.

JENKINS, Henry \& CARPENTIER, Nico. Theorizing Participatory Intensities: A

Conversation about Participation and Politics. Convergence, n. 19, v. 3, pp. 265-286, 2013.

JURAN, Joseph M. Juran on Leadership for Quality. Nova Iorque: Simon and Schuster, 2003.

KELLNER, Douglas. Critical Theory: Marxism and Modernity. Baltimore: Johns Hopkins University Press, 1989.

KENDALL, Gavin \& WICKHAM, Gary. Using Foucault's Methods. Londres: Sage, 1999.

LACLAU, Ernesto. Emancipation(s). Londres: Verso, 1996.

\& MOUFFE, Chantal. Hegemony and Socialist Strategy: Towards a Radical Democratic Politics. Londres: Verso, 1985.

LEPIK, Krista. Governmentality and Cultural Participation in Estonian Public Knowledge Institutions. Tese de doutorado. Tartu: University of Tartu Press, 2013. Acesso em: 2 Set. 2015. Disponível em:

$<$ http://dspace.utlib.ee/dspace/bitstream/handle/10062/32240/lepik_krista_2.pdf?sequence=4>

LUKES, Steven. Power: A Radical View. Basingstoke: Macmillan, 1984.

LURY, Celia. Consumer Culture. Cambridge: Polity, 2011.

MCQUAIL, Denis. Journalism as a Public Occupation: Alternative Images. In:

CARPENTIER, Nico; PRUULMANN-VENGERFELDT, Pille; NORDENSTRENG, Kaarle; HARTMANN, Maren; VIHALEMM, Peeter; CAMMAERTS, Bart; NIEMINEN, Hannu \& OLSSON, Tobias (org.). Democracy, Journalism and Technology: New Developments in an Enlarged Europe. The Intellectual Work of the 2008 ECREA Media and Communication Doctoral Summer School, pp. 47-59. Tartu: Tartu University Press, 2008.

MELUCCI, Alberto. Nomads of the Present: Social Movements and Individual Needs in Contemporary Society. Filadélfia: Temple University Press, 1989.

MORTON, Lois; BITTO, Ella; OAKLAND, Mary \& SAND, Mary. Accessing Food Resources: Rural and Urban Patterns of Giving and Getting Food. Agriculture \& Human Values, n. 25, v. 1, pp. 107-119, 2008. 
MOUFFE, Chantal. The Democratic Paradox. Londres: Verso, 2000.

On the Political. Londres: Routledge, 2005.

NEESON, Jeanette M. Commoners: Common Right, Enclosure and Social Change in

England, 1700-1820. Cambridge: Cambridge University Press, 1996.

PATEMAN, Carole. Participation and Democratic Theory. Cambridge: Cambridge

University Press, 1970.

REAL, Michael R. Exploring Media Culture: A Guide. Thousand Oaks: Sage, 1996.

RITZER, George. Modern Sociological Theory. Boston: McGraw-Hill, 2008.

ROEMER, Michael K. Ritual Participation and Social Support in a Major Japanese

Festival. Journal for the Scientific Study of Religion, n. 46, v. 2, pp. 185-200, 2007.

SHARMA, Rajendra Kumar. Fundamentals of Sociology. Nova Deli: Atlantic Publishers \& Dist, 1996.

SIBEON, Roger. Rethinking Social Theory. Londres: Sage, 2004.

VANDER STICHLE, Alexander \& LAERMANS, Rudi. Cultural Participation in Flanders. Testing the Culture Omnivore Thesis with Population Data. Poetics, n. 34, pp. 45-56, 2006.

WARD, Stephen. Ethics and the Media: An Introduction. Cambridge: Cambridge University Press, 2011.

WASKO, Janet \& MOSCO Vincent (org.). Democratic Communications in the Information Age. Toronto e Norwood: Garamond Press e Ablex, 1992.

WEGERICH, Kai \& WARNER, Jeroen. The Politics of Water: A Survey. Londres: Routledge, 2004. 